\title{
The History of the Austronesian Languages
}

Comparative-historical linguists have divided the fourteen hundred or so languages of the Pacific into three broad groups. About 450 are classified as belonging to the Austronesian family, a very large family of languages with another six or seven hundred members spoken outside the Pacific Basin. Seven hundred or so languages spoken on the island of New Guinea, or on islands not far from it, belong to a number of apparently unrelated families. All are grouped under the cover term Papuan. The two hundred Australian languages belong to a third broad genetic grouping. We know much more about both the present and the past of the Austronesian languages of the Pacific than we do about the Papuan or Australian languages. For this reason I discuss the history of the Austronesian languages first.

\subsection{The Austronesian Family}

The Austronesian language family is one of the two largest language families in the world in number of member languages. (The other is the BenueCongo family in Africa.) The family as a whole has somewhere between a thousand and twelve hundred languages, spoken by almost three hundred million people. ${ }^{1}$ Map 12 shows the distribution of Austronesian languages. Outside the Pacific Basin, Austronesian languages are spoken in Taiwan, in Malaysia and a few small pockets on the Asian mainland, in Madagascar, and in almost all of island Southeast Asia. All the languages of the Philippines and almost all the languages of Indonesia (excluding most of Irian Jaya) are Austronesian.

About 450 Austronesian languages are spoken within the Pacific region. These include all the languages of Polynesia, Micronesia, Fiji, New Caledonia, and Vanuatu, as well as almost all the languages of Solomon Islands. Only about one quarter of the languages of the New Guinea area belong 


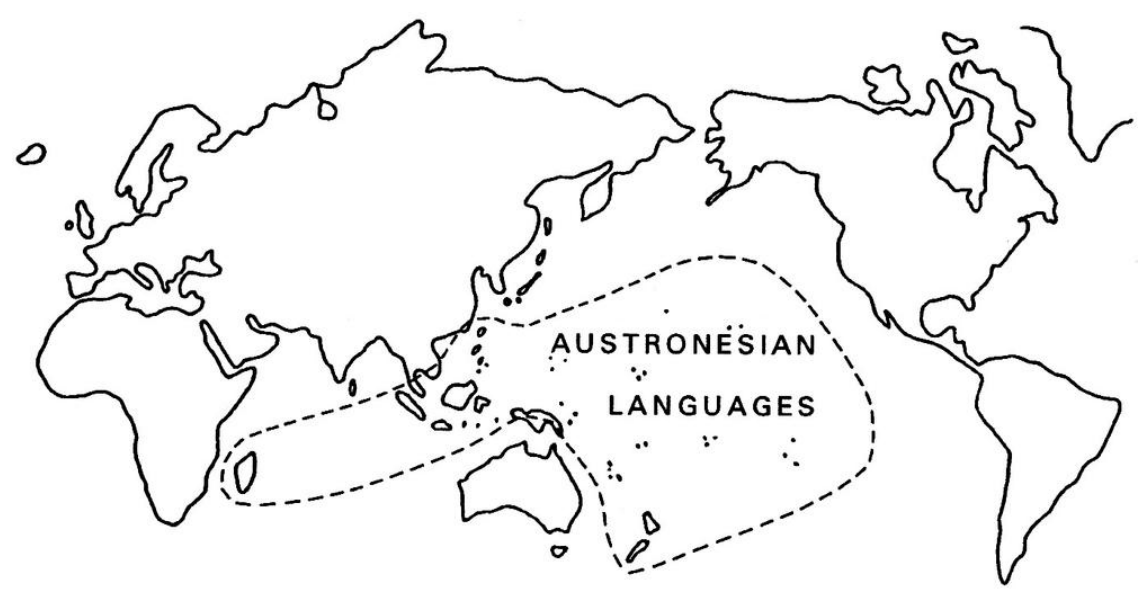

Map 12. Austronesian Languages

to this family, however. Speakers of these languages generally occupy New Guinea's offshore islands and some coastal areas, but very few inhabit inland areas.

While linguists are still not in full agreement as to the major subgroups of Austronesian, figure 6 shows one widely accepted view of the higher-order branches of this family. Nearly all of the Austronesian languages discussed in this book belong to the Oceanic subgroup. The family tree suggests an Asian origin for speakers of Austronesian, and the archaeological evidence tends to corroborate this.

\subsection{The Oceanic Languages}

Two languages spoken in Micronesia, Palauan and Chamorro, belong to one of the Western Malayo-Polynesian subgroups of Austronesian, and the Austronesian languages of the western part of Irian Jaya belong to the South Halmahera-West New Guinea subgroup. All of the other Austronesian languages in the Pacific belong to the Oceanic subgroup. This subgroup was originally established by the German linguist Dempwolff (1934-1938). He referred to it as Urmelanesisch 'Proto Melanesian.' All Oceanic languages share a number of phonological, grammatical, and lexical innovations that are absent from the other Austronesian languages.

\subsubsection{Internal Relationships of the Oceanic Languages}

Scholars have been debating the internal relationships of Oceanic for some time. They agree that the initial branching of Oceanic was in the western 
part of the Pacific, but the poor state of our knowledge of Melanesian languages has made it difficult to determine just what that initial branching looked like. Fijian and the Polynesian languages have been thoroughly studied for more than a century, and their interrelationships are fairly clear. They form, however, only one small subsubgroup of Oceanic, and studying them has not helped a great deal in determining the overall structure of the Oceanic subgroup.

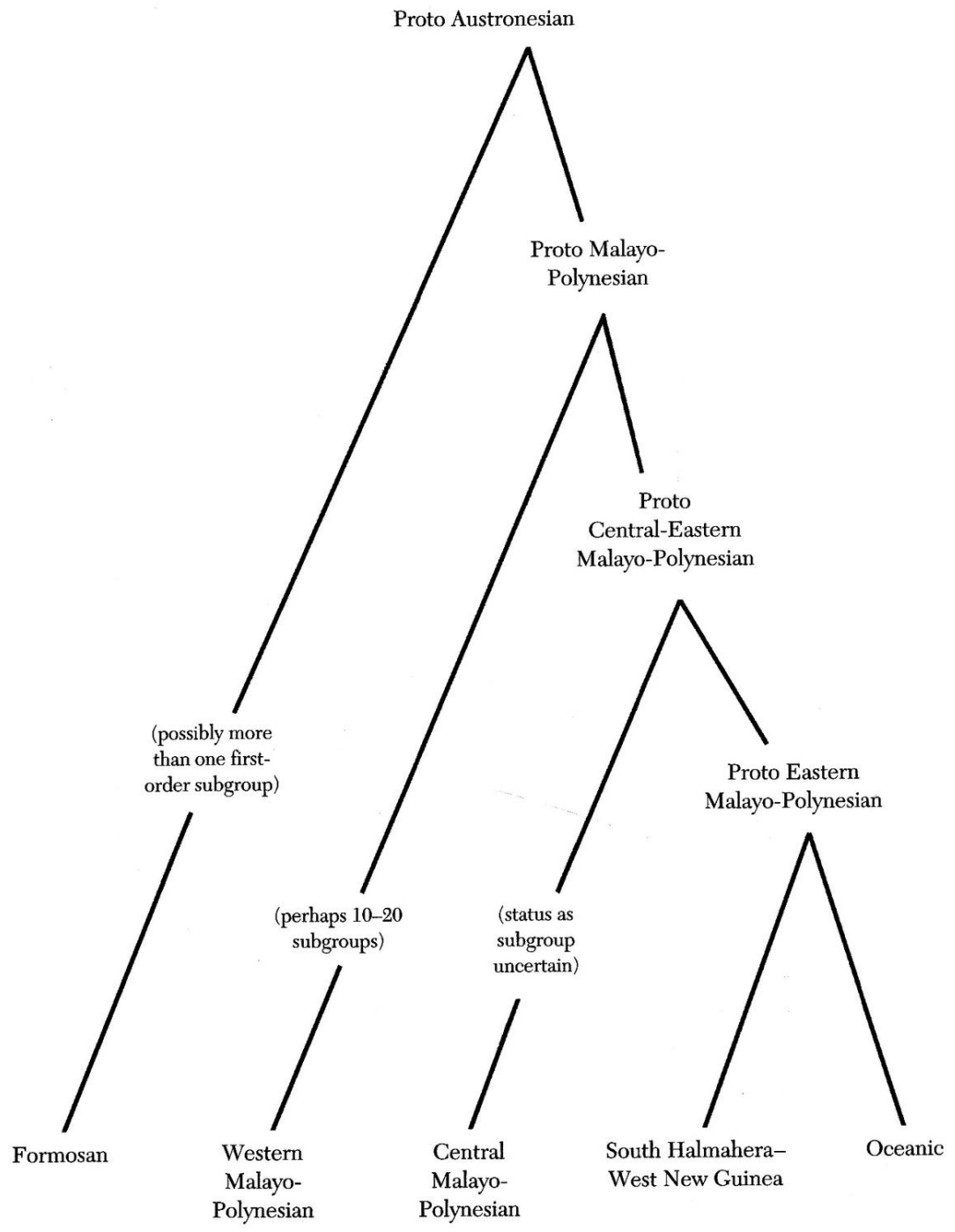

Figure 6. An Austonesian Family Tree 
Only in fairly recent years has a coherent picture of the Oceanic subgroup begun to emerge. Currently the groups within this subgroup include:

1. Yapese, spoken on the island of Yap in Micronesia (Ross 1995). This may prove to form part of the Admiralty Islands group.

2. The Admiralty Islands group, namely, the languages of Manus and neighboring islands to the north of the New Guinea mainland.

3. The Saint Matthias Islands group, two languages spoken on small islands immediately to the north of New Ireland in Papua New Guinea. This also may prove to be part of the Admiralty Islands group.

4. The Western Oceanic group, a very large grouping consisting of:

a. The North New Guinea subgroup, comprising all the Oceanic languages of western and southern New Britain plus those spoken along the northern coast of Papua New Guinea from just south of the Markham Valley westward to the Irian Jaya border.

b. The Papuan Tip subgroup, all the Oceanic languages of the Papuan mainland and the neighboring islands.

c. The Meso-Melanesian subgroup, made up of the Oceanic languages of northern and eastern New Britain, New Ireland, Bougainville (and their offshore islands), and the Oceanic languages of the western half of the Solomon Islands (excluding a handful of Polynesian Outlier languages-see 3.2.2 below).

d. The Sarmi-Jayapura subgroup, made up of the Oceanic languages of the northeast coast of Irian Jaya (Ross 1996). (These are included here because they may turn out to be part of the North New Guinea subgroup.)

5. The Southeast Solomons group includes the Oceanic languages of Guadalcanal, Malaita, and Makira, plus Bughotu on Isabel. This group may possibly also include the languages of Utupua and Vanikoro in the Temotu Province of Solomon Islands, though it is more likely that these form one or even two separate subgroups.

6. The Southern Oceanic group (Lynch 1997), consisting of:

a. The North-Central Vanuatu subgroup, in which are the nonPolynesian languages of north and central Vanuatu from the Torres Islands in the north to Efate in the central south.

b. The Southern Melanesian subgroup, with the non-Polynesian languages of Southern Vanuatu (Erromango, Tanna, and Aneityum), New Caledonia, and the Loyalty Islands.

7. The Micronesian group, all non-Polynesian Oceanic languages in geographical Micronesia, excluding Yapese; note that the status of Nauruan within this group is still problematic. 


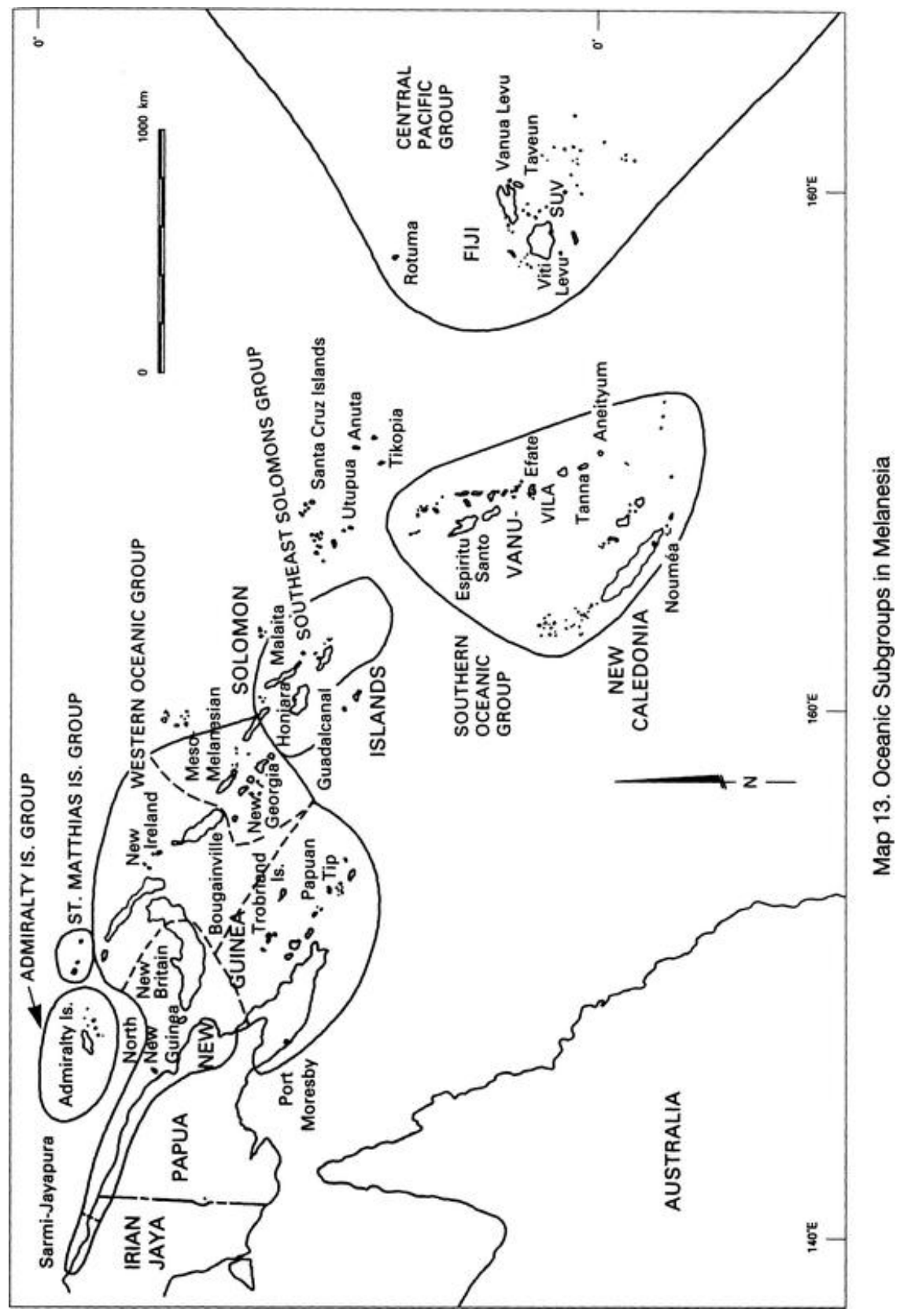


8. The Central Pacific group, consisting of Rotuman, the languages of Fiji, and all Polynesian languages, including the Polynesian Outliers discussed below. ${ }^{2}$

Attempts have been made to try to link two or more of these groupings together into a higher-order group, but they have so far been unsuccessful. Groups 5-8 above have recently been linked into a putative Central-Eastern Oceanic subgroup (Lynch, Ross, and Crowley 1998) whose validity is still being investigated. Because of this, trying to present a family tree of Oceanic would serve no real purpose at this stage of our research.

\subsubsection{Oceanic Subgroups and Geographical Regions}

Given the subgrouping of Oceanic just outlined, it should be obvious that the boundaries dividing the three traditional geographical-cultural regions of the Pacific-Melanesia, Micronesia, and Polynesia-do not correspond to the linguistic facts. About twenty languages are spoken in the geographical area known as Polynesia. Outside Polynesia are fourteen other languages that are very clearly genetically "Polynesian." These are referred to as Polynesian Outliers, and most scholars assume that they are the result of migrations into Melanesia and Micronesia from western Polynesia after its settlement by the ancestors of the modern Polynesians. Table 2 gives a list, with locations, of the fourteen Polynesian Outliers. (See also maps 4, 6-9). Figure 7 shows the interrelationships of the Polynesian languages and their immediate relatives in the Central Pacific group. The primary split in Polynesian occurred between the Tongic subgroup (consisting of just Tongan and Niuean) and the Nuclear Polynesian subgroup (consisting of all other Polynesian languages including the Outliers). The closest Outliers' relatives within Polynesian appear to be Samoan, Tokelauan, Tuvaluan, East Uvea, East Futuna, Niuafo'ou, and Pukapuka. Although all the languages of Polynesia are Polynesian in the genetic sense, not all Polynesian languages are spoken in Polynesia.

In Micronesia the situation is somewhat different. The "Micronesian" subgroup consists of most, but not all, of the languages of geographical Micronesia. Not only are two Polynesian Outliers, Nukuoro and Kapingamarangi, spoken in Micronesia, but Yapese appears to be a single member of a subgroup separate from all other Oceanic languages. To complicate matters further, the nature of the relationship of Nauruan to the other Micronesian languages is unclear, and Palauan and Chamorro are not even Oceanic languages at all, but have as their closest relatives languages in Indonesia and the Philippines.

Nowhere, however, is the mismatch between so-called cultural areas and linguistic classification more glaring than in Melanesia. Hundreds of 
Table 2. Polynesian Outliers

\begin{tabular}{lll}
\hline $\begin{array}{l}\text { Country or territory } \\
\text { Federated States of Mi- } \\
\text { cronesia }\end{array}$ & $\begin{array}{l}\text { Location } \\
\text { Nukuoro Island }\end{array}$ & $\begin{array}{l}\text { Language } \\
\text { Nukuoro }\end{array}$ \\
& Kapingamarangi Island & Kapingamarangi \\
Papua New Guinea & Nukuria Island & Nukuria \\
& Mortlock Island & Takuu \\
& Tasman Island & Nukumanu \\
Solomon Islands & Ontong Java & Luangiua \\
& Stewart Island & Sikaiana \\
& Rennell Island, Bellona & Rennellese \\
& Island & \\
& Duff Island & Pileni \\
& Tikopia Island, Anuta & Tikopia-Anuta \\
& Island & \\
& Emae Island & Emae \\
Panuatu & Port Vila harbor & Ifira-Mele \\
& Futuna Island, Aniwa & West Futuna \\
& Island & \\
New Caledonia & Ouvéa, Loyalty Islands & Fagauvea (West \\
& & Uvea) \\
\hline
\end{tabular}

Papuan languages are spoken in Melanesia, as are a number of Oceanic languages, including a dozen or so Polynesian Outliers (see table 3).

But more important is the fact that, although we can speak of a Polynesian subgroup, and even of a Micronesian subgroup, that have some correlation with geography, there is no such thing as a Melanesian subgroup of Oceanic. Of the eight major subgroups of Oceanic, six are located wholly or partly in Melanesia.

\subsection{The Settlement of Oceania}

Linguists construct hypotheses about the interrelationships of languages to attempt to find out about the past. These theories about past languages and language splits generally lead to theories about the origins and migrations of peoples. In many cases, one can compare linguistic and archaeological hypotheses in an effort to put both on a firmer footing.

\subsubsection{Origins of Oceanic Speakers}

The Oceanic subgroup's position on the Austronesian family tree (figure 6) indicates that the speakers of Proto Oceanic migrated from Southeast Asia 


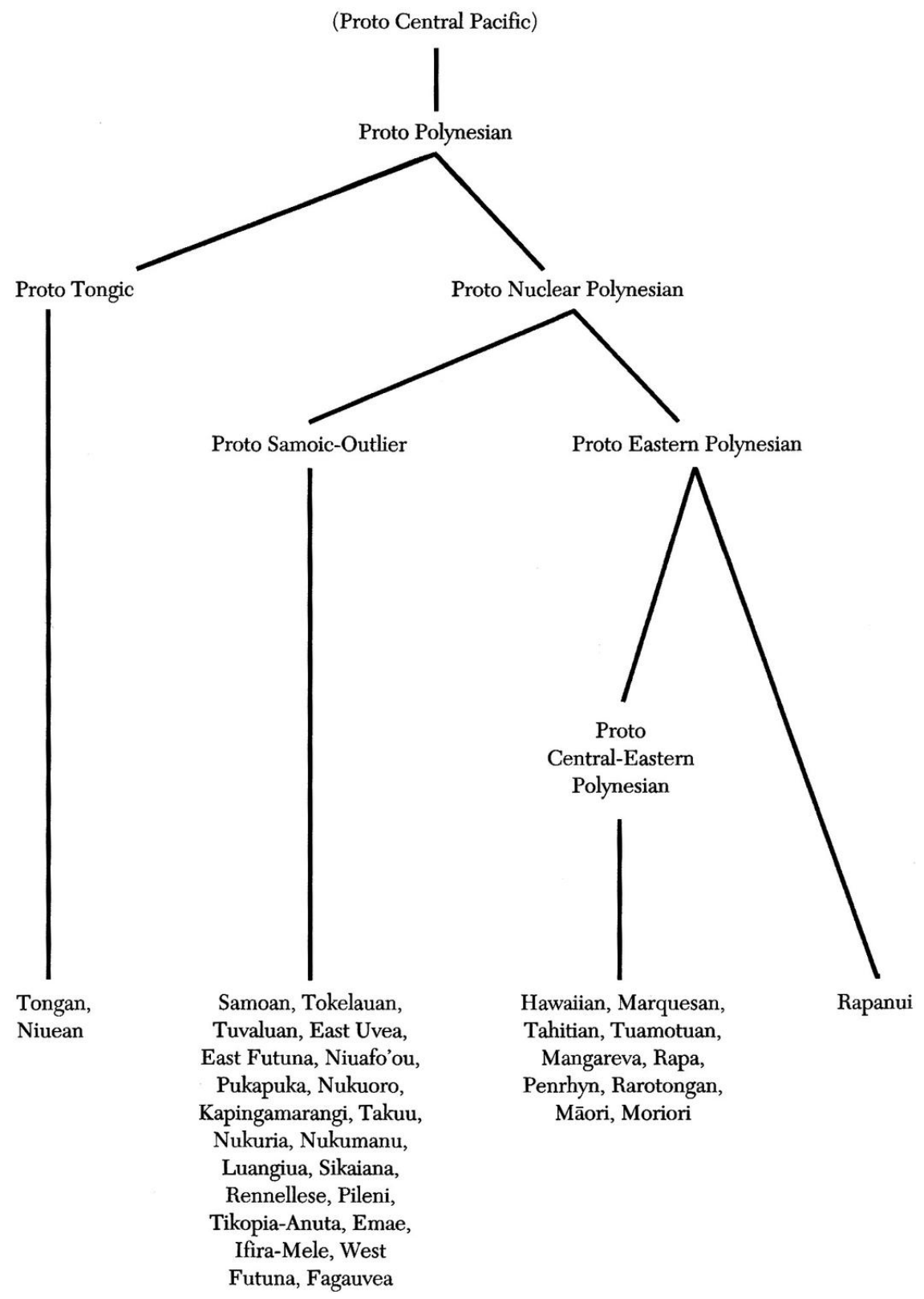

Figure 7. The Polynesian Subgroup 
Table 3. Languages of Melanesia

\begin{tabular}{lrrr}
\hline & Austronesian & Papuan & Total \\
New Caledonia & 28 & - & 28 \\
Vanuatu & 105 & - & 105 \\
Solomon Islands & 56 & 7 & 63 \\
Papua New Guinea & 210 & 540 & 750 \\
Irian Jaya & 45 & 160 & 205 \\
Totals & 444 & 707 & 1151 \\
\hline
\end{tabular}

to the Pacific region. This thesis is almost universally accepted. Some evidence suggests that the closest external relatives of the Austronesian languages may be (1) the Thai-Kadai group of languages, spoken mainly in Thailand and Laos, and (2) the languages of the neighboring Austroasiatic group, spoken mainly in Cambodia and Vietnam. Both of these groups also have members in southern China and in parts of Malaysia. Archaeologists suspect that dramatic improvements in agricultural practices, accompanied by significant population growth, led to expansions of human populations on the Southeast Asian mainland around 5,000 B.C. (Bellwood 1995).

The Austronesians were one of these populations. The linguistic family tree presented in figure 6 is compatible with the archaeological evidence pointing to an Austronesian homeland on the Asian mainland. The first noticeable expansion was into Taiwan, and then, after some centuries, from Taiwan to the Philippines. Later some Austronesian speakers migrated to Malaysia, Indonesia, and Madagascar.

The closest relatives of Oceanic are its immediate western neighbors in the Cenderawasih Bay area and the Halmahera Islands in western Irian Jaya. The immediate ancestors of the Proto Oceanic speakers migrated from eastern Indonesia through western Irian Jaya into the Bismarck Archipelago (Manus, New Britain, and New Ireland), and settled there-possibly around the Willaumez Peninsula in New Britain-for some time. Map 14 gives some idea of the various migrations.

\subsubsection{The Dispersal of Oceanic Speakers}

Oceanic speakers were not the first to arrive in the New Guinea area; speakers of Papuan languages had been there for a long time. The New Britain area, for example, has been settled for more than thirty thousand years, and parts of the mainland of New Guinea for much longer even than that. Contact between the original Papuan-speaking settlers and the invading 


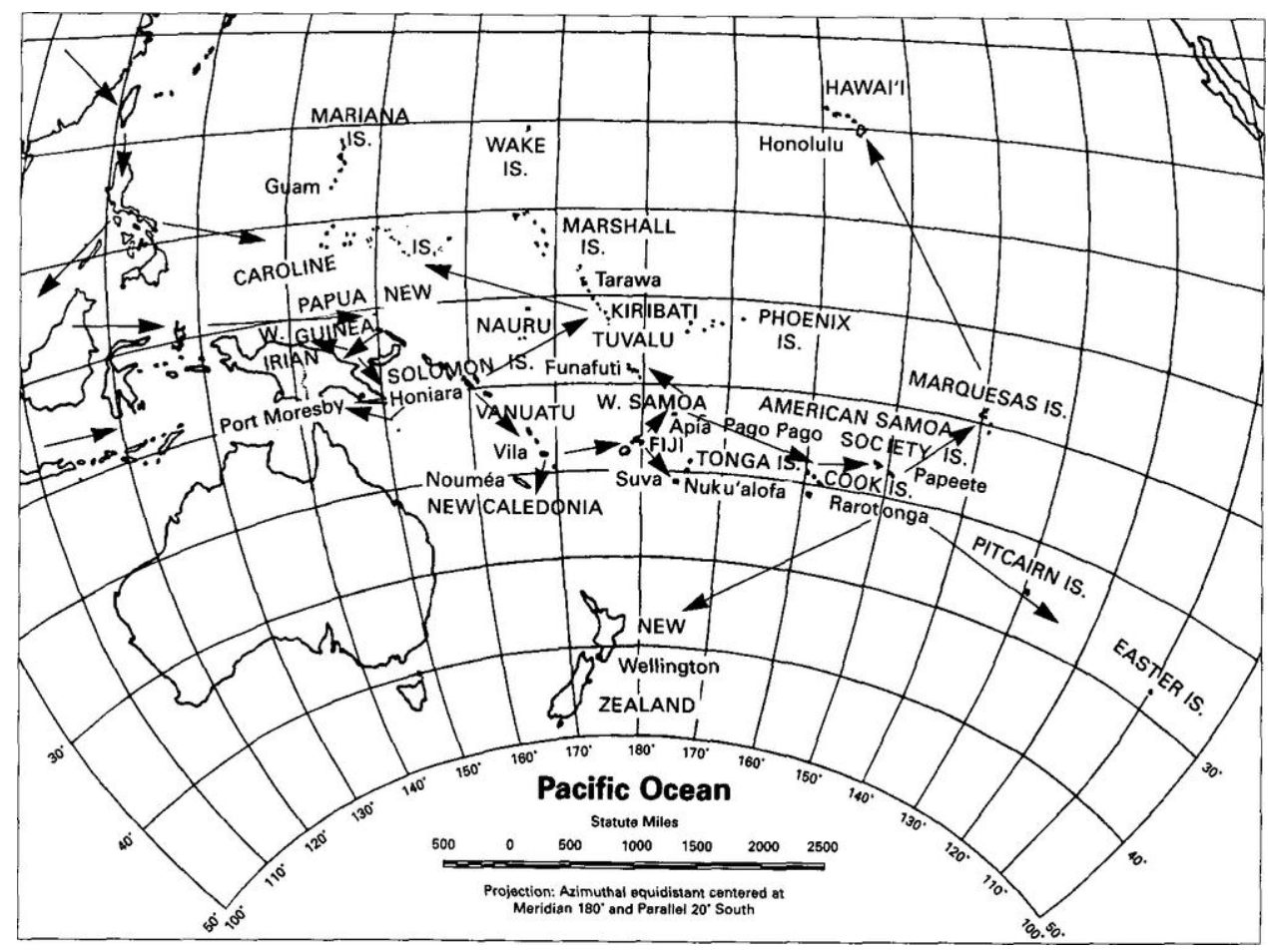

Map 14. Austronesian Migrations

Austronesians must have been varied in nature. In some situations the two groups probably engaged in open warfare. In others, the relationship would have been uneasy but not particularly hostile. Yet others no doubt involved total integration and intermarriage.

Some speakers of Proto Oceanic and its early descendants limited their settlements, moving slowly to settle the Admiralties and New Britain. Others went farther: Yap may have been settled from the Admiralties, for example, as were New Ireland and the western Solomons. Oceanic speakers also crossed the Vitiaz Strait to reach the New Guinea mainland, with one group progressively settling the north coast from east to west, and another moving into the Milne Bay area and the south coast.

Some Oceanic speakers seem to have been more adventurous still. If indeed they originated in the New Britain area, they have left no trace there, but seem to have moved first southeast into the Solomons, then south into northern and central Vanuatu and north into Micronesia, probably the Kiribati-Marshall Islands area, from which location they settled the rest of Micronesia. There were also movements further south, into southern Vanu- 
atu, the Loyalty Islands, and New Caledonia, and further east to Fiji, from where Polynesia was settled. Map 14 outlines these movements.

We should be careful, however, not to think of all of these migrations as major colonizing expeditions. Spriggs (1995), for example, suggests that there were probably initial long-distance scouting parties, followed by more than one movement of people along fairly well defined routes. Back-migrations of some people also took place. The migrations may have been deliberate, as such factors as population pressure, food shortages, or political turmoil forced people to seek somewhere else to live. They may also have been accidental, at least initially, as fishermen were blown off course and ended up on new islands. Many settlements succeeded, but a great number no doubt failed because of disease, attacks by speakers of Papuan languages, and all kinds of other reasons.

Such factors complicate the neat splitting of communities suggested by family trees. On the one hand, a language community may not have actually split, but rather slowly diversified as contact between its subgroups became less and less intense. On the other hand, different related languages could have influenced each other, blurring any innovations that might have been developing in one or another of them. Speed of settlement is another complicating factor. In the islands east of the Bismarcks no one seems to have stayed in one place long enough for telltale linguistic innovations to appear. Under these circumstances, definitive higher-order subgroups of Oceanic are hard to establish.

If the settlement of the Pacific proceeded in the direction and at the speed discussed above, it begins to make sense that Micronesians and Polynesians, although originating in Melanesia, nevertheless physically resemble their Southeast Asian ancestors more than they do Melanesians. Some Oceanic speakers moved through Melanesia quickly enough to retain Asian genetic features, and these people "became" Polynesians and Micronesians. Others remained in Melanesia, where centuries of intermarriage with the physically different Papuan speakers have led to quite different genetic developments (Pawley and Ross 1995, 60).

\subsubsection{Dating Dispersals: The "Lapita People"}

Trying to establish a chronological framework for these migrations purely on linguistic grounds is presently-and will probably remain-impossible. A family tree provides relative datings of language divisions, telling us that one such split occurred before or after another, but it does not offer any absolute dating.

In the 1950s and 1960s, linguists made an attempt to derive actual dates from lexicostatistical data. ${ }^{3}$ (The term for this is glottochronology.) Concrete 
dates for the breakup of Proto Indo-European and its various subgroups were, for example, proposed. Glottochronology, however, was strongly criticized by many scholars, not only because of some of the dates it generated, but also because of inherent weaknesses in its methodology and underlying assumptions. The practice has been almost universally abandoned.

But although there is no linguistic technique for determining absolute dates for divisions in protolanguages or for migrations, linguists can try to match their relative dating sequences with archaeological evidence, which is on surer ground when it comes to absolute dating. In the Oceanic region, this cooperative enterprise has led to some interesting results.

Archaeologists use the term Lapita to refer to a distinctive style of pottery. (The name comes from a place in New Caledonia, one of the first sites excavated with this pottery.) The term Lapita culture refers to the cultural complex associated with this pottery style, including the introduction of pigs, dogs, and chickens; distinctive stone adzes and shell ornaments; the development of larger villages; and the intensification of agriculture (Spriggs 1995; 116-118).

Lapita culture first appears in the archaeological record of the Bismarck Archipelago about 1600 B.C. It seems to have reached as far as Vanuatu and New Caledonia by about 1200 B.C., and Fiji and western Polynesia by about 1000 B.C. In Vanuatu and islands farther south and east, Lapita people were the first settlers: There is no evidence of any pre-Lapita people (Papuans or others) in eastern Melanesia and Polynesia, and this absence of competition for land would have made settlement much easier than it was farther north and west.

This notion of a very rapid movement of people through island Melanesia correlates very well with the linguistic subgrouping that I discussed in the last section: That is, the fact that the Oceanic group seemed to have a number of first-order subgroups (a "flat" tree), rather than two or three subgroups that themselves have only two or three subsubgroups, suggests fairly quick movement over a wide area. Much slower settlement patterns would have allowed more time for distinctive innovations and would present a more layered family tree, with the eastern languages much lower down the tree than the western ones.

Archaeologists tell us that the original Polynesians settled in the SamoaTonga area about 1000 B.C., remaining in that area for five hundred or even a thousand years. At around the turn of the era, some moved into eastern Polynesia, while others migrated to the western Pacific to establish the Outliers. By about A.D. 1000, all the major eastern Polynesian island groups had been settled (Bellwood 1978; 318).

In Micronesia, there is evidence that the Mariana Islands may have been 
settled from Southeast Asia about 1000 B.c. The rest of Micronesia, however, appears to have been settled for only about two thousand years-probably by Lapita people from somewhere in Melanesia, though neither linguistics nor archaeology is able to tell us precisely where.

Significantly less archaeological work has been done in the western and northern parts of the Pacific than in the eastern part, so that linguists working on the Polynesian languages, who are dealing with a relatively short period, have reliable archaeological information with which to correlate their findings. But those working in Melanesia and Micronesia have to deal with a longer period of time, much less archaeological information against which to test their hypotheses, and, in some areas at least, occupation by pre-Oceanic peoples.

\subsubsection{Rapid Diversification in Melanesia}

Many linguists have commented on and tried to explain the much greater diversity exhibited by the Austronesian languages of Melanesia than by any other part of the Austronesian family. This is partly a function of time. Austronesian languages have had more time to change in Melanesia than in Polynesia or Micronesia, and so appear less similar to each other. But there is more to the problem-and to Austronesian language history-than the time factor. After all. Austronesians have not been in Melanesia for countless eons longer than they have been in Polynesia and Micronesia.

Some of the Austronesian languages of Melanesia seem to have changed more rapidly than others. This is due in part to contact between Austronesian and Papuan languages. Fairly clear evidence shows that some languages of the Oceanic subgroup have changed radically as a result of contact with Papuan languages. Among the most radical are languages like Magori and Maisin in Papua New Guinea, where linguists have had difficulty in deciding whether or not they are Austronesian at all! So the history of the Austronesian languages of Melanesia-especially western Melanesia-is complicated by the fact that they not only neighbor Papuan languages but have in many cases been in intimate contact with them.

But certainly all of the major differences between Melanesian languages cannot be explained by Papuan contact. Many of the more aberrant Oceanic languages in Melanesia, like those of New Caledonia, are far away from the nearest Papuan language. Rapid change can be an internal matter as well as an external one, and many of the differences between languages in this region have come about without external influence. The small scale of many Melanesian societies can allow changes to spread more quickly than they might in larger societies, although smallness does not cause rapid change. 
The notion of the emblematic function (Grace 1981) of language in Melanesia is an important one to mention here. Linguistic differences can be important as badges of membership in a particular social group, and people often focus on these differences as markers of in-group or out-group status (in the same way that young people in many societies use slang expressions to mark their in-group status). In Melanesia especially, differences between neighboring languages may have been exaggerated-even manufactured-in order to preserve this emblematic function. Such a process leads to more rapid diversification than normally expected.

\subsection{Reconstructing Culture}

Much of the effort of comparative-historical linguists has gone into the reconstruction of the vocabulary of Proto Oceanic. An examination of this reconstructed vocabulary gives us insights into the culture of the speakers of the language in a number of ways:

1. An examination of words that can be reconstructed for Proto Oceanic can help us make inferences about the culture of the speakers of that language.

2. Identification of widespread cultural items for which terms can not be reconstructed for Proto Oceanic suggests that such items were more recent introductions.

3. An examination of reconstructed Proto Austronesian words not reflected in Proto Oceanic can indicate which original Austronesian cultural items were lost or abandoned by Oceanic speakers as they moved eastward into the Pacific.

As an example of the last point, we can reconstruct Proto Austronesian words referring to different kinds of rice and millet, and to rice and millet cultivation, but no such reconstructions can be made for Proto Oceanic. Presumably these crops were abandoned by Oceanic speakers in their migration from Southeast Asia to the Pacific.

Terms we can reconstruct for Proto Oceanic embrace a wide cultural range. ${ }^{4} \mathrm{~A}$ few of the subject areas are:

- Canoes and fishing. Terms for two types of outrigger canoes (large and small), outrigger float and boom, matting sail, paddle, bailer, launching rollers, rudder, and anchor, as well as terms for various parts of the canoe and for steering and sailing. There are also many reconstructed terms for a number of aspects of fishing technology, and of course names of many different kinds of fish, shellfish, and crustaceans. 
- Pottery. Various kinds of pots, clay and techniques of clay pot manufacture, decorations, and accessories like lids, as well as terms for different kinds of cooking (roasting, boiling, steaming, stone or earth oven, etc.).

- Food crops. Several kinds of yam, taro, banana, pandanus, breadfruit, sago, and sugar cane, as well as terms associated with horticultural practices.

- Fruits and nuts. A wide range of terms relating to the coconut has been reconstructed, including those for different stages of growth and parts of the fruit or tree. The words for a number of fruit and nut trees, for betel nut, and for plants like ginger and turmeric have also been reconstructed.

- Animals and birds. Proto Oceanic terms in this area include words for wild and domesticated pig, dog, fowl, rat, bandicoot, cassowary, cuscus (possum), and numerous bird names.

- Social structure. A fairly complete set of kinship terms has been reconstructed, as have terms relating to chieftainship and the societal hierarchy.

These and other reconstructed words paint the following picture of early Oceanic culture. The original speakers of Proto Oceanic were clearly a maritime people. They used outrigger canoes, fished with hooks and nets, and generally exploited the resources of the maritime environment. They grew a number of crops, including yam, taro, banana, and sugar cane, and gathered fruits and nuts. They had domesticated fowls, pigs, and dogs (and suffered the rat!), used the spear and the bow and arrow for hunting or warfare, made clay pots, and built houses with shelves and platforms (as well as probably building more temporary shelters in gardens or on the beach). They had a fairly hierarchical society, with chiefs and probably other social ranks as well. They believed in gods or spirits and probably practiced sorcery.

But some words cannot be reconstructed for Proto Oceanic despite the fact that the items they name are found in most parts of the Pacific today. The sweet potato, for example, is grown and eaten across the Pacific, yet there is no Proto Oceanic reconstruction for it. Apparently the sweet potato was introduced after the dispersal of Oceanic speakers. Archaeological evidence confirms this. Other items that also fall into this category include the pawpaw and the cassava (manioc). Our linguistic evidence, particularly when paired with the archaeological testimony, gives us a partial understanding of Pacific prehistory, although much remains to be done. 